\title{
Breast Cancer Patients Treated by Helical Tomotherapy, Intensity-modulated Radiotherapy, and Volumetric Arc Therapy: Comparison of Lung Doses
}

\author{
WK Ho, RKC Ngan, CWY Yip, FKH Lee, JCF Lui \\ Department of Clinical Oncology, Queen Elizabeth Hospital, Jordan, Hong Kong
}

\begin{abstract}
Introduction: We compared the dosimetry of three different radiotherapy $(R T)$ techniques: helical tomotherapy (TOMO), intensity-modulated RT (IMRT), and volumetric modulated arc therapy (VMAT) in patients with breast cancer when the conventional technique was unworkable.

Methods: We enrolled 16 patients that required treatment of residual internal mammary lymph node involvement $(n=9)$, with a planning target volume $(P T V)$ close to the borders of the tangential fields of the conventional RT technique $(n=5)$, and with synchronous breast tumours requiring bilateral breast irradiation $(n=2)$. Planning computed tomography contours of these patients were retrieved, and virtual $R T$ plans of all three techniques were developed for each patient for the purpose of dose comparison, with the objective of achieving optimal dose coverage to the PTV while minimising the lung dose and keeping the heart dose to the internationally recognised safe level. 42.56 Gy in 16 daily fractions was prescribed in all RT plans.

Results: The PTV coverage and hot spot dose were comparable among all RT plans. The doses to organs at risk were converted to 2 Gy equivalent using an $\alpha / \beta$ ratio of 3 for comparison. The mean lung dose (MLD), lung V5, and lung V20 were significantly lower using TOMO (MLD 10.2 Gy, V5:30.3\%, V20: 14.7\%), compared with IMRT (MLD 11.9 Gy, $p=0.006$; V5: 39.7\%, $p<0.001 ;$ V20: 20.6\%, $p=0.001)$ and VMAT (MLD 15.4 Gy, $p<0.001$; V5: $52.3 \%, p<0.001 ; \mathrm{V} 20: 27 \%, p<0.001)$. The mean heart dose was significantly lower using IMRT (12.1 Gy) compared with TOMO (15.5 Gy, $p=0.017)$ and VMAT (14.9 Gy, $p=0.005$ ).

Conclusion: TOMO achieved lower lung doses, in terms of V5, V2O and MLD, compared with IMRT and VMAT.
\end{abstract}

Key Words: Breast Neoplasms; Radiotherapy; Radiotherapy, intensity-modulated

\footnotetext{
Correspondence: Dr WK Ho, Department of Clinical Oncology, Queen Elizabeth Hospital, Jordan, Hong Kong Email: hwk757@ha.org.hk
}

Submitted: 12 Feb 2018; Accepted: 2 Oct 2018.

Contributors: WKH and RKCN designed the study. WKH, CWYY, FKHL and JCFL acquired the data. WKH and RKCN analysed the data, drafted the manuscript, and had critical revision of the manuscript for important intellectual content. All authors had full access to the data, contributed to the study, approved the final version for publication, and take responsibility for its accuracy and integrity.

Conflicts of Interest: As an editor of the journal, RKC Ngan was not involved in the peer review process. Other authors have disclosed no conflicts of interest.

Funding/Support: This research received no specific grant from any funding agency in the public, commercial, or not-for-profit sectors.

Ethics Approval: This study has been approved by the Research Ethics Committee of the Hospital Authority (Ref KC/KE-18-0002/ER-2). The requirement for patient consent was waived by the Research Ethics Committee. 


\title{
中文摘要
}

\section{螺旋斷層放療、調強放療和容積弧形調強放療治療乳腺癌患者： 肺部劑量的比較}

\author{
何宏光、顏繼昌、李家豪、葉惠儀、吕卓徽 \\ 引言 : 在傳統技術不可行的情況下, 比較三種治療乳腺癌患者的放療技術的劑量學, 包括螺旋斷層 \\ 放療（TOMO）、調強放療（IMRT）和容積弧形調強放療（VMAT）。 \\ 方法 : 研究納入 16 例患者, 包括內乳區殘餘淋巴結照射 $(n=9)$ 、計劃靶區 $(P T V)$ 接近常規放療 \\ 邊界 $(\mathrm{n}=5)$, 及因同時性乳腺癌須進行雙側乳房照射 $(\mathrm{n}=2)$ 。檢索這些患者的電腦掃描輪廓, \\ 並針對每位患者制定所有三種技術的放療計劃以進行劑量比較, 以實現PTV最佳劑量覆蓋範圍同時 \\ 盡量減少肺劑量, 並保持心臟劑量達到國際公認的安全水平。所有放療技術均規定劑量為42.56 Gy, \\ 分16次完成。 \\ 結果 : 三種放療技術的計劃靶區覆蓋範圍和熱點劑量均相若。危及器官的劑量轉換為 $2 \mathrm{~Gy}(\alpha / \beta$ 比 \\ 率為3）作比較。與另外兩種技術相比（IMRT：平均肺劑量MLD $11.9 \mathrm{~Gy}, \mathrm{p}=0.006 ; \mathrm{V} 539.7 \%$ ， \\ $\mathrm{p}<0.001 ; \mathrm{V} 2020.6 \%, \mathrm{p}=0.001 ; \mathrm{VMAT}:$ MLD $15.4 \mathrm{~Gy}, \mathrm{p}<0.001 ; \mathrm{V} 552.3 \%, \mathrm{p}<0.001 ; \mathrm{V} 20$ \\ $27 \%, \mathrm{p}<0.001)$, 使用TOMO的MLD ( $10.2 \mathrm{~Gy})$ 、肺V5（30.3\%）和肺V20（14.7\%）均顯著較 \\ 低。IMRT ( $12.1 \mathrm{~Gy})$ 的平均心藏劑量也明顯低於TOMO ( $15.5 \mathrm{~Gy}, \mathrm{p}=0.017)$ 和VMAT $(14.9 \mathrm{~Gy}$, \\ $\mathrm{p}=0.005)$ 。
}

結論 : 與IMRT和VMAT相比, TOMO的V5, V20和平均肺部劑量較低。

\section{BACKGROUND}

Postoperative adjuvant radiotherapy (RT) has proven benefits in reducing locoregional recurrence and improving overall survival in patients with breast cancer. ${ }^{1}$ However, it can be associated with significant pulmonary and cardiac adverse effects. ${ }^{2-8}$

Conventional RT technique consists of two tangential opposing wedged photon beams that cover the chest wall or breast, with or without an anterior photon beam to cover the supraclavicular and apical axillary region. ${ }^{9}$ With its short RT planning and treatment times, satisfactory target volume coverage, low incidence of RT toxicities, and good locoregional control, this technique is by far the most popular methodology employed in RT for breast cancer worldwide. ${ }^{10}$

However, application of the conventional RT technique is not feasible in all patients. Despite the use of computed tomography (CT) simulation in RT planning, the conventional RT technique cannot ensure adequate coverage of a target volume extending to the internal mammary chain (IMC) nodes, or when the planning target volume (PTV) is close to the borders of the conventional RT fields. Moreover, when both breasts or the chest wall have to be irradiated in patients with synchronous bilateral breast cancers, employing the conventional technique on both sides may lead to significant overlap of irradiated volumes over the anterior chest wall near the midline, resulting in an increased risk of radiation toxicity. In these cases, other advanced RT techniques may be employed, but the optimal technique in terms of minimal radiation dose to the lungs remains to be defined. At Queen Elizabeth Hospital, Hong Kong, helical tomotherapy (TOMO), intensity-modulated RT (IMRT), and volumetric modulated arc therapy (VMAT) have been used in this clinical scenario. IMRT delivers radiation by multiple treatment fields formed by many small intensity-modulated photon beams. ${ }^{11}$ By changing the intensity of each beam and the shape of each treatment field with compensators or a multileaf collimator (MLC), IMRT conforms the radiation dose to the target volume and reduces unwanted irradiation of adjacent organs at risk (OARs). Unlike IMRT, in which the RT gantry 
needs to stop and start at multiple gantry angles to deliver treatment, VMAT can deliver radiation continuously in multiple arcs, thus significantly reducing treatment time. ${ }^{12}$ In TOMO, a fan of intensity-modulated photon pencil beams is delivered over 360 degrees around the patient by a rotating ring gantry while the patient is moved through the bore of the RT machine. ${ }^{13}$

The aim of this virtual dosimetric study was to compare the radiation dose to the lungs among the TOMO, IMRT, and VMAT techniques.

\section{METHODS \\ Patient Selection}

From February 2014 to November 2016, 24 patients with breast cancer in our institution received RT to the breast(s) or chest wall using TOMO, IMRT, or VMAT. Twenty-three patients received adjuvant RT after breast surgery for their stage I-IV breast cancer, while one other patient refused upfront surgery and received palliative TOMO alone to the unresected breast and regional nodal regions. Eight of the 24 patients were excluded from this study due to the following exclusion criteria: concomitant irradiation of bone metastasis, distant lymph node or soft tissue metastasis; previous RT to the neck; and male breast cancer. Therefore, a total of 16 patients were included in this study. Conventional RT technique was considered undesirable in these 16 patients owing to the need to irradiate residual IMC lymph node involvement $(n=9)$, the location of the PTV close to borders of the conventional RT fields $(n=5)$, and a diagnosis of synchronous breast tumours requiring bilateral breast irradiation $(\mathrm{n}=2)$.

\section{Patient Preparation and Image Acquisition}

All patients were treated in the supine position on a breast board (Extended Wing Board, MTWB08T; CIVCO Radiotherapy, Orange City [IA], US), with both arms abducted. The skin dose to the surgical scar was enhanced by routine application of a 1-cm wax bolus in patients who had undergone mastectomy. Boluses were also used to enhance the dose to the chest skin if there had been skin involvement, extensive lymphovascular invasion, or a report of involvement of the anterior (superficial) resection margin.

A simulation CT scan was performed in all patients in the treatment position on the breast board for RT planning with a 16-slice Brilliance CT Big Bore scanner (Philips Medical Systems, Cleveland [OH], US) using 3-mm slice separation from mid-neck to mid-abdomen.

\section{Definition of Target Volumes and Organs at Risk}

RT target volumes were defined according to the Radiation Therapy Oncology Group's breast cancer atlas for RT planning and its consensus definition published in 2009. ${ }^{14}$ Clinical target volume (CTV) included the ipsilateral chest wall and/or breast in all patients. Ipsilateral level I to III axillary and supraclavicular nodal regions were also included in the CTV according to the stage of breast cancer. The IMC nodal region was included when there was evidence of IMC nodal involvement. PTV was created by adding a $1-\mathrm{cm}$ margin in all directions to the CTV. $3 \mathrm{~mm}$ from the body surface was trimmed from the PTV if wax bolus was not applied.

The lungs and heart were manually contoured as the OARs. The heart was contoured from the level of the pulmonary trunk to the apex, including the pericardium, but excluding the major vessels.

\section{Radiotherapy Planning}

Patient setup and CT simulation were performed according to the standard institutional protocols of the Department. Each of the 16 patients had been treated by TOMO, IMRT, or VMAT techniques. The planning CT image data used for their specific treatment were retrospectively used for this dosimetric comparison study. For each patient, three new virtual RT plans were generated based on the planning CT image data, using TOMO, IMRT and VMAT techniques, respectively, for the purpose of dose comparison.

The CT data were transferred to the two RT treatment planning systems: Eclipse 3D version 13.0 (Varian Medical Systems Inc., Palo Alto [CA], US) for IMRT and VMAT planning, and TomoHD version 2.1.1 (Accuray Inc., Madison [WI], US) for TOMO planning. We used $6 \mathrm{MV}$ photon beams in all the RT plans. Both IMRT and VMAT were delivered by a linear accelerator (Clinac 23EX, Varian Medical Systems) using the sliding window technique with a MLC. ${ }^{15}$ Seven coplanar fields were used in IMRT. For VMAT, a double partial arc plan, with an arc angle from 200 degrees to 50 degrees clockwise for right breast irradiation (arc angle is mirrored for left breast irradiation), was used. For TOMO (TomoHD, Accuray Inc.), the following planning parameters were used: field width $2.51 \mathrm{~cm}$, pitch 0.43 , modulation factor 3 , helical mode delivery. A total dose of $42.56 \mathrm{~Gy}$ in 16 daily fractions was used for all RT plans. ${ }^{16,17}$ 
The primary goal was to ensure adequate PTV coverage, by delivering $100 \%$ of the prescribed dose to $95 \% \pm 1 \%$ of the PTV as homogeneously as possible, avoiding hot spots exceeding $115 \%$ of the prescribed dose. The secondary goal was to minimise OAR doses. The dosimetric constraints for RT dose optimisation of PTV and OARs in this study were based on the department protocol (Table 1), which was in line with the QUANTEC (Quantitative Analyses of Normal Tissue Effects in the Clinic) review recommendations. ${ }^{5,6}$ The percentage volume of the lungs receiving $\geq 5$ Gy (lung V5) has been shown to be associated with the risk of radiation pneumonitis (RP). ${ }^{5,18-21}$ Therefore, after fulfilling the OAR requirements specified in Table 1, lung V5 would be minimised while keeping the hot spot $\leq 115 \%$.

\section{Methodology and Parameters for Plan Comparison}

In this study, the primary endpoint was the radiation doses received by the lungs. For each patient, the mean lung dose (MLD), lung V5, and the percentage volume of the lungs receiving $\geq 20$ Gy (lung V20) were measured. The secondary endpoint was the radiation doses to the heart. The mean heart dose (MHD) and the percentage volumes of the heart receiving $\geq 25$ Gy and $\geq 45$ Gy (heart $\mathrm{V} 25$ and heart V45, respectively) were measured.

\section{Statistics}

The dosimetric parameters for the lungs and heart in the IMRT, TOMO, and VMAT plans were compared using the Wilcoxon signed rank test for statistical significance. A difference of $\mathrm{p}<0.05$ was considered statistically significant.

\section{RESULTS}

At a median follow-up interval of 16.8 months, all patients were alive and without locoregional failure. No major coronary events (myocardial infarction, coronary revascularisation, or death from ischaemic heart disease)

Table 1. Dosimetric constraints for radiotherapy planning and optimisation.

\begin{tabular}{lll}
\hline Structures & Objectives & Priority \\
\hline PTV & V100\% $=95 \%( \pm 1 \%)$ of the PTV & High \\
& volume & \\
Heart & V $25<10 \%$ & High-medium \\
Bilateral lungs & V20 $<30 \%$ and V $5<40 \%$ & High-medium \\
\hline
\end{tabular}

Abbreviations: PTV = planning target volume; $\mathrm{V} 5=$ percentage volume receiving $\geq 5$ Gy; V20 = percentage volume receiving $\geq 20$ Gy; V25 = percentage volume receiving $\geq 25$ Gy. or symptomatic radiation-induced lung disease was observed in any patient. The patient characteristics are summarised in Table 2.

The PTV coverage was satisfactory and comparable among the three different RT techniques, achieving $95 \% \pm 1 \%$ coverage of the PTV with the prescribed dose in all RT plans. The mean conformity indices (volume receiving the prescribed dose divided by PTV) for TOMO, IMRT, and VMAT were 1.16, 1.18, and 1.22 , respectively, suggesting that the treatment volume corresponded well to the PTV in all RT plans. The hot spots in all RT plans did not exceed $115 \%$ of the prescribed dose. The doses to various OARs were converted to 2 Gy equivalents using an $\alpha / \beta$ ratio of 3 for comparison. ${ }^{22}$

In the two patients with synchronous breast cancers requiring bilateral breast irradiation, in order to achieve

Table 2. Patient characteristics $(n=16)$.

\begin{tabular}{lc}
\hline Age (years) & \\
Range & $41-77$ \\
Mean & 52.3 \\
Laterality & \\
Left breast cancer & $6(38 \%)$ \\
Right breast cancer & $8(50 \%)$ \\
Synchronous bilateral breast cancer & $2(13 \%)$ \\
T staging* & \\
T1 & $4(25 \%)$ \\
T2 & $4(25 \%)$ \\
T3 & $5(31 \%)$ \\
T4 & $3(19 \%)$ \\
N staging* & \\
NO & $3(19 \%)$ \\
N1 & $1(6 \%)$ \\
N2 & $5(31 \%)$ \\
N3 & $7(44 \%)$ \\
Overall staging* & \\
Stage I & $2(13 \%)$ \\
Stage II & $1(6 \%)$ \\
Stage III & $12(75 \%)$ \\
Stage IV & $1(6 \%)$ \\
Type of surgery & \\
Modified radical mastectomy & $13(81 \%)$ \\
Mastectomy + AD & $12(75 \%)$ \\
Mastectomy + SNB & $1(6 \%)$ \\
Rreast conservation surgery (lumpectomy + SNB) & $2(13 \%)$ \\
Rystemic therapies & $1(6 \%)$ \\
Neoadjuvant chemotherapy & \\
Adjuvant chemotherapy & $4(25 \%)$ \\
Adjuvant tamoxifen or aromatase inhibitor & $9(56 \%)$ \\
Neoadjuvant/adjuvant herceptin & $12(75 \%)$ \\
\hline & $7(44 \%)$ \\
\hline
\end{tabular}

Abbreviations: $A D=$ axillary dissection; $A J C C=$ American Joint Committee on Cancer; SNB = sentinel lymph node biopsy.

* AJCC TNM Classification 7th edition, 2010. 
the target volume coverage by the prescribed dose described above, IMRT and VMAT techniques resulted in doses to the lungs and heart exceeding the dose limits to OARs in the department protocol (Tables 3 and 4). TOMO, on the other hand, met the dose limits to OARs while fulfilling the PTV coverage requirements in these two patients. In the remaining 14 patients, all the RT plans for TOMO, IMRT, and VMAT met the dose limits to OARs laid down in the department protocol.

The average total (ipsilateral and contralateral) MLD, total lung V5, and total lung V20 among the 16 patients

Table 3. Dose limits of organs at risk in the department protocol.

\begin{tabular}{|c|c|}
\hline Organ at risk & Dose limit \\
\hline $\begin{array}{l}\text { Spinal cord } \\
\text { Spinal cord PRV } \\
\text { Heart } \\
\text { Bilateral lungs } \\
\text { Oesophagus } \\
\text { Liver }\end{array}$ & $\begin{array}{l}D_{\text {max }} \leq 45 \text { Gy } \\
D_{\text {max }} \leq 50 \text { Gy } \\
V 25 \leq 10 \% \\
V 20 \leq 35 \% \\
D_{\text {mean }} \leq 20 \mathrm{~Gy} \\
D_{\text {mean }} \leq 34 \text { Gy } \\
D_{\text {mean }} \leq 28 \mathrm{~Gy}\end{array}$ \\
\hline
\end{tabular}

Abbreviations: $\mathrm{D}_{\max }=$ maximum dose; $\mathrm{D}_{\text {mean }}=$ mean dose; $\mathrm{PRV}=$ planning organ at risk volume; V20 = percentage volume receiving $\geq 20$ Gy; V25 = percentage volume receiving $\geq 25$ Gy. included in this study were significantly lower using TOMO (MLD 10.2 Gy, V5: 30.3\%, V20: 14.7\%), compared with those using IMRT (MLD $11.9 \mathrm{~Gy}$, $\mathrm{p}=0.006 ; \mathrm{V} 5: 39.7 \%, \mathrm{p}<0.001 ; \mathrm{V} 20: 20.6 \%, \mathrm{p}=0.001)$ and with those using VMAT (MLD $15.4 \mathrm{~Gy}, \mathrm{p}<0.001$; V5: 52.3\%, p < 0.001; V20: 27\%, p < 0.001) [Table 5].

The average MHD was significantly lower using IMRT (12.1 Gy), compared with that using TOMO (15.5 Gy, $\mathrm{p}=0.017)$ and that using VMAT $(14.9 \mathrm{~Gy}, \mathrm{p}=0.005)$ [Table 5]. This significant difference was observed in patients with left breast cancer $(n=6)$ [MHD: $12.1 \mathrm{~Gy}$ for IMRT vs. 16.2 Gy for TOMO, p = 0.028] and with right breast cancer $(n=8)$ [MHD: 7.9 Gy for IMRT vs. 13.5 Gy for TOMO, $\mathrm{p}=0.012]$.

Similar results in the lung and heart doses were observed when the two patients with bilateral breast cancer, with unacceptable RT plans by IMRT and VMAT, were excluded from the analysis (Table 6).

TOMO had lower ipsilateral lung doses, but higher contralateral lung doses compared with IMRT, due to the intrinsic differences in radiation beam arrangement (Table 7).

Table 4. Doses to the lungs and heart in the two patients with synchronous breast cancers mandating bilateral breast irradiation.

\begin{tabular}{|c|c|c|c|c|c|c|}
\hline & \multicolumn{2}{|c|}{ TOMO } & \multicolumn{2}{|c|}{ IMRT } & \multicolumn{2}{|c|}{ VMAT } \\
\hline & Patient 1 & Patient 2 & Patient 1 & Patient 2 & Patient 1 & Patient 2 \\
\hline Mean lung dose & 16.9 Gy & 18 Gy & $22.6 \mathrm{~Gy}$ & 21.2 Gy & 30.6 Gy & 24.6 Gy \\
\hline Lung V5 & $71.2 \%$ & $66.7 \%$ & $79.2 \%$ & $69.2 \%$ & $92.4 \%$ & $85.4 \%$ \\
\hline Lung V20 & $28.1 \%$ & $31.6 \%$ & $44.1 \%$ & $43.5 \%$ & $61.5 \%$ & $50.1 \%$ \\
\hline Mean heart dose & 20.1 Gy & 22.4 Gy & 29.1 Gy & 27.5 Gy & 37.4 Gy & 31.5 Gy \\
\hline Heart V25 & $5.2 \%$ & $6.7 \%$ & $63.8 \%$ & $59.8 \%$ & $91.4 \%$ & $75.9 \%$ \\
\hline Heart V45 & $0.03 \%$ & $0.7 \%$ & $14.5 \%$ & $14.2 \%$ & $36.8 \%$ & $23.8 \%$ \\
\hline
\end{tabular}

Abbreviations: IMRT = intensity-modulated radiotherapy; TOMO = helical tomotherapy; V5 = percentage volume receiving $\geq 5$ Gy; V20 = percentage volume receiving $\geq 20$ Gy; V25 = percentage volume receiving $\geq 25$ Gy; V45 = percentage volume receiving $\geq 45$ Gy; VMAT $=$ volumetric modulated arc therapy.

Table 5. Mean parameters of lung and heart doses in the 16 patients included in this study. *

\begin{tabular}{lcccccr}
\hline & TOMO & IMRT & VMAT & \multicolumn{3}{c}{$p$ Value } \\
\cline { 5 - 7 } & & & & TOMO vs IMRT & TOMO vs VMAT & IMRT vs VMAT \\
\hline MLD (bilateral lungs, Gy) & $10.2 \pm 3.1$ & $11.9 \pm 4.3$ & $15.4 \pm 5.5$ & 0.006 & $<0.001$ & 0.001 \\
V5 (bilateral lungs, \%) & $30.3 \pm 15.7$ & $39.7 \pm 15.8$ & $52.3 \pm 18.0$ & $<0.001$ & $<0.001$ & $<0.001$ \\
V20 (bilateral lungs, \%) & $14.7 \pm 6.7$ & $20.6 \pm 10$ & $27.0 \pm 13$ & 0.001 & $<0.001$ & 0.001 \\
MHD (Gy) & $15.5 \pm 3.1$ & $12.1 \pm 7.3$ & $14.9 \pm 7.9$ & 0.017 & 0.109 & 0.005 \\
Heart V25 & $6.3 \pm 1.3$ & $11.8 \pm 19.8$ & $16.2 \pm 26.7$ & 0.469 & 0.179 & 0.01 \\
Heart V45 & $0.3 \pm 0.4$ & $2.4 \pm 4.8$ & $4.3 \pm 10.4$ & 0.043 & 0.006 & 0.15 \\
\hline
\end{tabular}

Abbreviations: IMRT = intensity-modulated radiotherapy; MHD = mean heart dose; MLD = mean lung dose; TOMO = helical tomotherapy; V20 = percentage volume receiving $\geq 20$ Gy; V25 = percentage volume receiving $\geq 25$ Gy; V45 = percentage volume receiving $\geq 45$ Gy; V5 = percentage volume receiving $\geq 5$ Gy; VMAT = volumetric modulated arc therapy.

* Data are shown as mean \pm standard deviation, unless otherwise indicated. 
Table 6. Lung and heart doses in the 14 patients, after excluding the two patients with bilateral breast cancer.*

\begin{tabular}{lcccccc}
\hline & TOMO & IMRT & VMAT & \multicolumn{3}{c}{$p$ Value } \\
\cline { 5 - 7 } & & & & & TOMO vs IMRT & TOMO vs VMAT \\
\hline MLD (bilateral lungs, Gy) & $9.2 \pm 1.3$ & $10.5 \pm 1.8$ & $13.7 \pm 2.8$ & 0.017 & 0.001 & 0.001 \\
V5 (bilateral lungs, \%) & $24.8 \pm 4.5$ & $34.8 \pm 8.8$ & $47.1 \pm 11.6$ & 0.002 & 0.001 & 0.001 \\
V20 (bilateral lungs, \%) & $12.6 \pm 3.14$ & $17.3 \pm 4.6$ & $22.9 \pm 6.7$ & 0.003 & 0.001 & 0.002 \\
MHD (Gy) & $14.6 \pm 2.2$ & $9.7 \pm 3.8$ & $12.1 \pm 1.8$ & 0.001 & 0.003 & 0.015 \\
Heart V25 (\%) & $6.3 \pm 1.4$ & $4.6 \pm 3.5$ & $6.6 \pm 3.4$ & 0.064 & 0.509 & 0.001 \\
Heart V45 (\%) & $0.3 \pm 0.4$ & $0.7 \pm 1.3$ & $0.6 \pm 0.8$ & 0.142 & 0.019 & 0.480 \\
\hline
\end{tabular}

Abbreviations: IMRT = intensity-modulated radiotherapy; MHD = mean heart dose; MLD = mean lung dose; TOMO = helical tomotherapy; V5 = percentage volume receiving $\geq 5$ Gy; V20 = percentage volume receiving $\geq 20$ Gy; V25 = percentage volume receiving $\geq 25$ Gy;

V45 = percentage volume receiving $\geq 45$ Gy; VMAT = volumetric modulated arc therapy.

* Data are shown as mean \pm standard deviation, unless otherwise indicated.

Table 7. Ipsilateral and contralateral lung doses in the 14 patients, after excluding the two patients with bilateral breast cancer.*

\begin{tabular}{lccc}
\hline & TOMO & IMRT & VMAT \\
\hline MLD to ipsilateral lung (Gy) & $13.5 \pm 2.3$ & $17.9 \pm 3.6$ & $19.9 \pm 3.5$ \\
V5 to ipsilateral lung (\%) & $60.6 \pm 11.2$ & $78.8 \pm 11.9$ & $82 \pm 13.2$ \\
V20 to ipsilateral lung (\%) & $26.3 \pm 6.4$ & $37.4 \pm 9.5$ & $44.5 \pm 9.5$ \\
MLD to contralateral lung (Gy) & $4.3 \pm 0.5$ & $2.6 \pm 0.9$ & $5.2 \pm 1.4$ \\
V5 to contralateral lung (\%) & $18.3 \pm 8.8$ & $12.7 \pm 9.3$ & $34.7 \pm 16.9$ \\
V20 to contralateral lung (\%) & $0.4 \pm 0.5$ & $0.5 \pm 1.4$ & $1.4 \pm 1.9$ \\
\hline
\end{tabular}

Abbreviations: IMRT = intensity-modulated radiotherapy; MLD = mean lung dose; TOMO = helical tomotherapy; V5 = percentage volume receiving $\geq 5 \mathrm{~Gy}$; 20 = percentage volume receiving $\geq 20$ Gy; VMAT = volumetric modulated arc therapy.

* Data are shown as mean \pm standard deviation, unless otherwise indicated.

\section{DISCUSSION}

To the best of our knowledge, this is the first study reported in the literature that compares the radiation dose to the lungs among TOMO, IMRT, and VMAT in breast cancer patients unsuitable for conventional RT technique.

Our results show that TOMO is superior to IMRT and VMAT in bilateral breast cancers requiring synchronous bilateral chest wall irradiation, because only TOMO could fulfil the QUANTEC dose constraint recommendations for OARs without compromising the PTV dose coverage.

Our results also show that TOMO was associated with the least radiation dose to the lungs as measured by V5, V20 and MLD, when all the RT plans were generated based on the same set of QUANTEC dose constraint recommendations for the lungs and heart. In IMRT and
VMAT, the radiation fields are shaped by fixed primary jaws and MLCs to form a conformal treatment volume, but a small amount of radiation could 'leak' through the MLC. ${ }^{23}$ In contrast, as TOMO uses a radiation beam with a narrow field width of $2.51 \mathrm{~cm}$ during the helical mode RT delivery, the craniocaudal borders were shielded by the primary jaws of the gantry rather than the MLC. The maximum MLC leakage was around $2 \%$, and only $0.25 \%$ for TOMO according to the product specifications from the manufacturers. As a result, TOMO could achieve better sparing of inadvertent radiation to the lungs (Figure 1). Studies have demonstrated correlation of lung V5, V20, and MLD values with RP, and it is well accepted that they should be kept as low as possible. ${ }^{6,7}$ The QUANTEC review recommended limiting lung V 20 to $\leq 30 \%$ to $35 \%$ and MLD to $\leq 20$ to 23 Gy in order to limit the risk of RP to $\leq 20 \% .{ }^{6}$ According to the Lyman model in QUANTEC review, which correlated RP risk and MLD, ${ }^{6}$ reducing the MLD from 11.9 Gy in IMRT to 10.2 Gy in TOMO could result in an absolute reduction of RP risk of $1.5 \%$ (Figure 2). The jaw tracking technique may reduce MLC leakage in IMRT and VMAT, thus reducing the unwanted radiation dose to the lungs. In a treatment by jaw tracking technique, the secondary jaws are moved dynamically with the MLC leaves to reduce MLC transmission. However, this new technique is only available in new-generation linear accelerators.

In the RT planning process, heart V25 was kept $\leq 10 \%$ as recommended by the QUANTEC review, ${ }^{5}$ which was postulated to be associated with $<1 \%$ probability of cardiac mortality 15 years after partial heart irradiation. ${ }^{16}$ In computing the various virtual RT plans for the different techniques, lowering the lung dose was found to increase the heart dose, and vice versa. In this virtual dosimetric study, MHD was not intentionally suppressed to the 

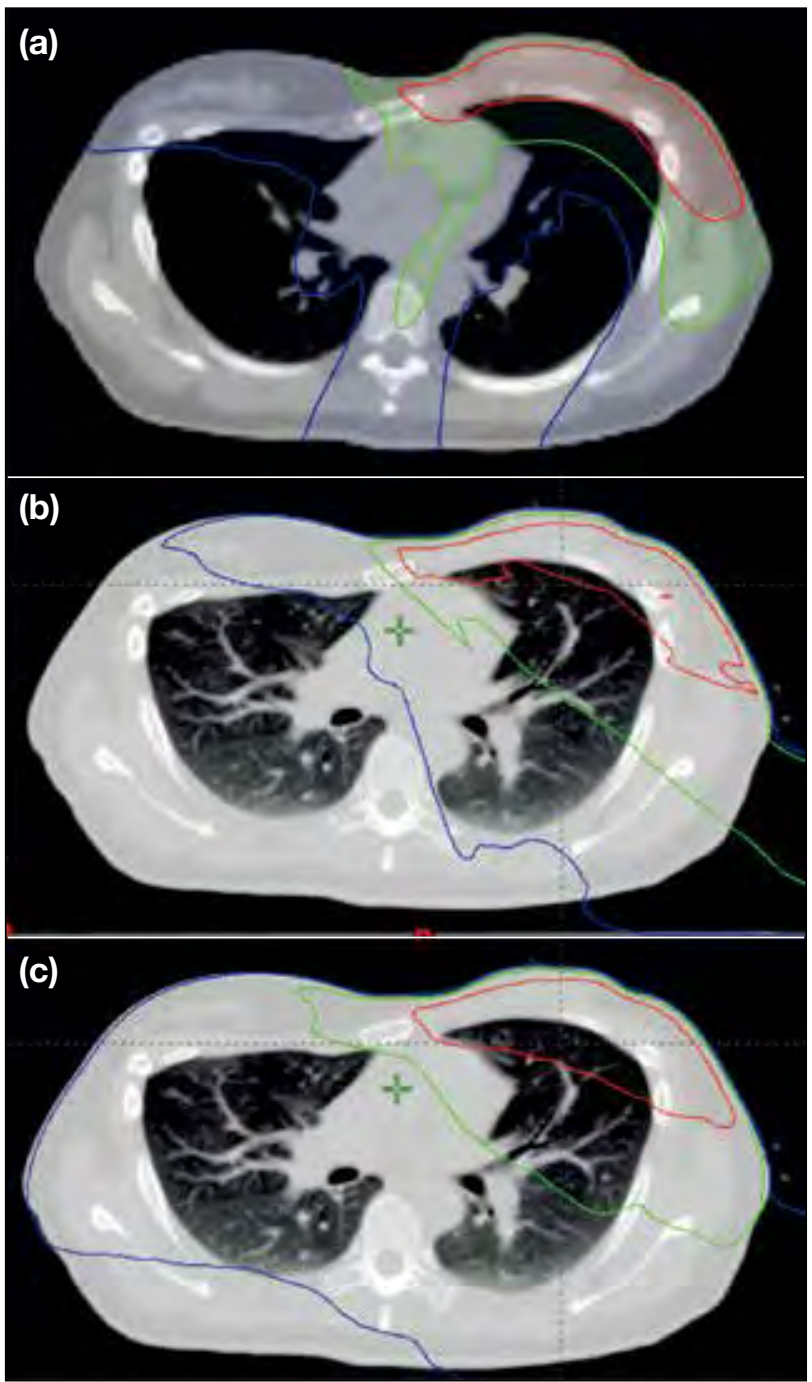

Figure 1. Planning computed tomography scans showing the isodose lines of 42.56 Gy (the prescribed dose) [red line], 20 Gy (green line), and 5 Gy (blue line) for (a) tomotherapy, (b) intensitymodulated radiotherapy, and (c) volumetric modulated arc therapy techniques.

lowest achievable level, since the primary objective of this study was to investigate how the lung doses could be minimised by the three techniques. In daily clinical practice, MHD should also be suppressed to as low as reasonably achievable, since there is evidence to show that MHD correlated with risk of major coronary events. ${ }^{24}$ The relatively low lung V20 achievable by the various techniques in this dosimetry study indicated room for further suppression of MHD, and optimal dose distribution between the lungs and heart may be varied for individual patients. Indeed, we suggest following a stricter set of dose constraints in the subgroup of patients with internal mammary node involvement as recommended by the United Kingdom Royal College

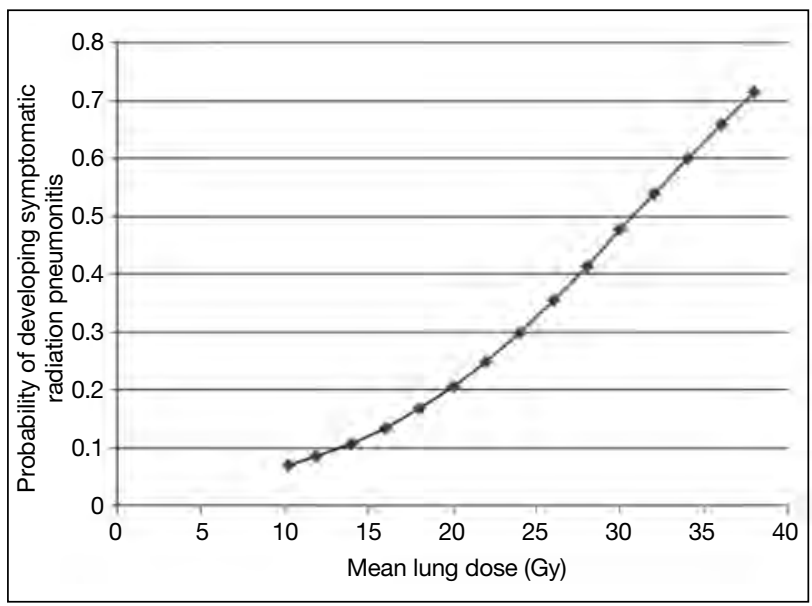

Figure 2. Lyman model correlating the radiation pneumonitis risk and mean lung dose.

of Radiologists consensus statements (heart V17 $<10 \%$, ipsilateral lung V17 $<35 \%$, mean contralateral breast dose $<3.5 \mathrm{~Gy}$, and MHD $<6 \mathrm{~Gy}$ ). ${ }^{25}$

There are some limitations to the present study. To facilitate comparison of lung doses among the three RT techniques, all the RT plans were computed to achieve coverage of $95 \% \pm 1 \%$ of the PTV covered by $100 \%$ of the prescribed dose, with similar conformity index and hot spot dose. Also, the present study included only those patients with breast cancer in whom computing an RT plan with low lung and heart doses could be difficult, because employing the conventional RT technique was considered unfeasible. It is conceivable that the predicted heart and lung doses in this virtual dosimetric study are higher than those in standard RT plans computed for patients with early breast cancer, which would be commonly encountered in clinical practice. Although statistically significant differences were observed in important dosimetric parameters such as MLD among the three RT techniques, another limitation of this study is the small sample size. Patients included in this study received advanced RT techniques for three different indications. A larger cohort, consisting of patients treated according to each indication, might allow clearer delineation of pulmonary and/or cardiac risks for different RT techniques used for different indications.

\section{CONCLUSION}

TOMO achieved lower lung doses, in terms of V5, V20 and MLD, compared with IMRT and VMAT in patients with breast cancer. 


\section{REFERENCES}

1. Clarke M, Collins R, Darby SC, Davies C, Elphinstone P, Evans $\mathrm{V}$, et al. Effects of radiotherapy and of differences in the extent of surgery for early breast cancer on local recurrence and 15year survival: an overview of the randomised trials. Lancet. 2005;366:2087-106. Crossref

2. McGale P, Darby SC, Hall P, Adolfsson J, Bengtsson NO, Bennet $\mathrm{AM}$, et al. Incidence of heart disease in 35,000 women treated with radiotherapy for breast cancer in Denmark and Sweden. Radiother Oncol. 2011;100:167-75. Crossref

3. Roychoudhuri R, Robinson D, Putcha V, Cuzick J, Darby S, Møller H. Increased cardiovascular mortality more than fifteen years after radiotherapy for breast cancer: a population-based study. BMC Cancer. 2007;7:9. Crossref

4. Berrington de Gonzalez A, Curtis RE, Gilbert E, Berg CD, Smith SA, Stovall M, et al. Second solid cancers after radiotherapy for breast cancer in SEER cancer registries. Br J Cancer. 2010;102:2206. Crossref

5. Gagliardi G, Constine LS, Moiseenko V, Correa C, Pierce LJ, Allen AM, et al. Radiation dose-volume effects in the heart. Int J Radiat Oncol Biol Phys. 2010;76(3 Suppl):S77-85. Crossref

6. Marks LB, Bentzen SM, Deasy JO, Kong FM, Bradley JD, Vogelius IS, et al. Radiation dose-volume effects in the lung. Int J Radiat Oncol Biol Phys. 2010;76(3 Suppl);S70-6. Crossref

7. Rodrigues G, Lock M, D’Souza D, Yu E, Van Dyk J. Prediction of radiation pneumonitis by dose-volume histogram parameters in lung cancer - a systematic review. Radiother Oncol. 2004;71:12738. Crossref

8. Gagliardi G, Lax I, Ottolenghi A, Rutqvist LE. Long-term cardiac mortality after radiotherapy of breast cancer - application of the relative seriality model. Br J Radiol. 1996;69:839-46. Crossref

9. Donovan E, Bleakley N, Denholm E, Evans P, Gothard L, Hanson $\mathrm{J}$, et al. Randomised trial of standard 2D radiotherapy (RT) versus intensity modulated radiotherapy (IMRT) in patients prescribed breast radiotherapy. Radiother Oncol. 2007;82:254-64. Crossref

10. Aref A, Thornton D, Youssef E, He T, Tekyi-Mensah S, Denton L, et al. Dosimetric improvements following 3D planning of tangential breast irradiation. Int J Radiat Oncol Biol Phys. 2000;48:156974. Crossref

11. International Atomic Energy Agency. Transition from 2-D Radiotherapy to 3-D Conformal and Intensity Modulated Radiotherapy. IAEA-TECDOC-1588. Vienna: IAEA; 2008: 26-9.

12. Teoh M, Clark CH, Wood K, Whitaker S, Nisbet A. Volumetric modulated arc therapy: a review of current literature and clinical use in practice. Br J Radiol. 2011;84:967-96. Crossref

13. Rong Y, Welsh JS. Dosimetric and clinical review of helical tomotherapy. Expert Rev Anticancer Ther 2011;11:309-20. Crossref

14. White J, Tai A, Arthur D, Buchholz T, MacDonald S, Marks L, et al. Breast cancer atlas for radiation therapy planning: consensus definitions. RTOG 2009. Available from: https://www.rtog.org/ LinkClick.aspx ?fileticket=vzJFhPaBipE=. Accessed Nov 2017.

15. Convery DJ, Rosenbloom ME. The generation of intensitymodulated fields for conformal radiotherapy by dynamic collimation. Phys Med Biol. 1992;37:1359-74. Crossref

16. Whelan T, MacKenzie R, Julian J, Levine M, Shelley W, Grimard $\mathrm{L}$, et al. Randomized trial of breast irradiation schedules after lumpectomy for women with lymph node-negative breast cancer. J Natl Cancer Inst. 2002;94:1143-50. Crossref

17. Whelan TJ, Pignol JP, Levine MN, Julian JA, MacKenzie R, Parpia S. Long-term results of hypofractionated radiation therapy for breast cancer. N Engl J Med. 2010;362:513-20. Crossref

18. Wang S, Liao Z, Wei X, Liu HH, Tucker SL, Hu CS, et al. Analysis of clinical and dosimetric factors associated with treatment-related pneumonitis in patients with non-small-cell lung cancer (NSCLC) treated with concurrent chemotherapy and threedimensional conformal radiotherapy. Int J Radiat Oncol Biol Phys. 2006;66:1399-407. Crossref

19. Jo IY, Kay CS, Kim JY, Son SH, Kang YN, Jung JY, et al. Significance of low-dose radiation distribution in development of radiation pneumonitis after helical-tomotherapy-based hypofractionated radiotherapy for pulmonary metastases. J Radiat Res. 2014;55:105-12. Crossref

20. Song CH, Pyo H, Moon SH, Kim TH, Kim DW, Cho KH. Treatment-related pneumonitis and acute esophagitis in non-smallcell lung cancer patients treated with chemotherapy and helical tomotherapy. Int J Radiat Oncol Biol Phys. 2010;78:651-8. Crossref

21. Wang SL, Liao ZX, Vaporciyan AA, Tucker SL, Liu H, Wei X, et al. Investigation of clinical and dosimetric factors associated with postoperative pulmonary complications in esophageal cancer patients treated with concurrent chemoradiotherapy followed by surgery. Int J Radiat Oncol Biol Phys. 2006;64:692-9. Crossref

22. Fowler JF. The linear-quadratic formula and progress in fractionated radiotherapy. Br J Radiol. 1989;62:679-94. Crossref

23. Liu HH, Wang X, Dong L, Wu Q, Liao Z, Stevens CW, et al. Feasibility of sparing lung and other thoracic structures with intensity-modulated radiotherapy for non-small-cell lung cancer. Int J Radiat Oncol Biol Phys. 2004;58:1268-79. Crossref

24. Darby SC, Ewertz M, McGale P, Bennet AM, Blom-Goldman U, Brønnum D, et al. Risk of ischemic heart disease in women after radiotherapy for breast cancer. N Engl J Med. 2013;368:98798. Crossref

25. The Royal College of Radiologists. Postoperative radiotherapy for breast cancer: UK consensus statements. November 2016. Available from: https://www.rcr.ac.uk/clinical-oncology/servicedelivery/postoperative-radiotherapy-breast-cancer-uk-consensusstatements. Accessed Nov 2017. 